Supporting Information

\title{
A novel amino-pillar[5]arene as a fluorescent probe for highly selective detection of $\mathrm{Au}^{3+}$ ions
}

Jun-Li Yang, Yun-Han Yang, Yu-Peng Xun, Ke-Ke Wei, Jie Gu, Mei Chen,

$$
\text { Li-Juan Yang }{ }^{a^{*} \square}
$$

School of Chemistry \& Environment, Key Laboratory of Intelligent Supramolecular

Chemistry at the University of Yunnan Province, National and Local Joint Engineering Research Center for Green Preparation Technology of Biobased Materials, Yunnan Minzu University, Kunming, P. R. China

* Corresponding author.

E-mail addresses: yangljyang@sina.com. 


\section{Materials}

1,4-Diethoxybenzene, paraformaldehyde, 1,2-dichloroethane, boron trifluoride etherate, chloroform, boron tribromide, ethanol, potassium carbonate, anhydrous acetonitrile, methyl chloroacetate, dichloromethane, anhydrous sodium sulphate, methanol, ethylenediamine, $n$-hexane, and hydrochloric acid were obtained from Aladdin Reagent Co. Ltd. $\mathrm{Ag}^{+}, \mathrm{Al}^{3+}, \mathrm{Ba}^{2+}, \mathrm{Bi}^{+}, \mathrm{Ca}^{2+}, \mathrm{Cd}^{2+}, \mathrm{Co}^{3+}, \mathrm{Cs}^{+}, \mathrm{Cu}^{2+}, \mathrm{Fe}^{2+}, \mathrm{Fe}^{3+}$, $\mathrm{Hg}^{2+}, \mathrm{K}^{+}, \mathrm{Li}^{+}, \mathrm{Mg}^{2+}, \mathrm{Na}^{+}, \mathrm{Pb}^{2+}, \mathrm{Sb}^{2+}, \mathrm{Sn}^{2+}, \mathrm{Sr}^{2+}, \mathrm{Ni}^{2+}, \mathrm{Au}^{3+}, \mathrm{Br}^{-}, \mathrm{I}^{-}, \mathrm{PO}_{4}^{3-}, \mathrm{HPO}_{4}{ }^{2-}, \mathrm{Cl}^{-}$, $\mathrm{HSO}_{3}{ }^{-}, \mathrm{CO}_{3}{ }^{2-}, \mathrm{HCO}_{3}^{-}, \mathrm{SO}_{4}{ }^{2-}, \mathrm{NO}_{3}{ }^{-}, \mathrm{NO}_{2}^{-}, \mathrm{F}^{-}\left(\mathrm{AgNO}_{3}, \mathrm{Al}\left(\mathrm{NO}_{3}\right)_{3} \cdot 9 \mathrm{H}_{2} \mathrm{O}, \mathrm{BaCl}_{2} \cdot 2 \mathrm{HO}_{2}\right.$, $\mathrm{Bi}\left(\mathrm{NO}_{3}\right)_{3} \cdot 5 \mathrm{H}_{2} \mathrm{O}, \mathrm{CaCl}_{2}, \mathrm{CdCl}_{2}, \mathrm{CoCl}_{2} \cdot 6 \mathrm{H}_{2} \mathrm{O}, \mathrm{Cs}_{2} \mathrm{CO}_{3}, \mathrm{CuSO}_{4} \cdot 5 \mathrm{H}_{2} \mathrm{O}, \mathrm{FeSO}_{4} \cdot 7 \mathrm{HO}_{2}$, $\mathrm{FeCl}_{3} \cdot 6 \mathrm{H}_{2} \mathrm{O}, \mathrm{HgCl}_{2}, \mathrm{KCl}, \mathrm{LiF}, \mathrm{MgSO}_{4} \cdot 7 \mathrm{H}_{2} \mathrm{O}, \mathrm{Na}_{2} \mathrm{SO}_{4}, \mathrm{~Pb}\left(\mathrm{NO}_{3}\right)_{2}, \mathrm{SbCl}_{3}, \mathrm{SnCl}_{2} \cdot 2 \mathrm{H}_{2} \mathrm{O}$, $\mathrm{SrCl}_{2} \cdot 6 \mathrm{H}_{2} \mathrm{O}, \mathrm{NiCl}_{2} \cdot 6 \mathrm{H}_{2} \mathrm{O}, \mathrm{HAuCl}_{4}, \mathrm{NaBr}, \mathrm{NaI}, \mathrm{Na}_{3} \mathrm{PO}_{4}, \mathrm{Na}_{2} \mathrm{HPO}_{4}, \mathrm{NaCl}, \mathrm{NaHSO}_{3}$, $\mathrm{Na}_{2} \mathrm{CO}_{3}, \mathrm{NaHCO}_{3}, \mathrm{Na}_{2} \mathrm{SO}_{4}, \mathrm{NaNO}_{3}, \mathrm{NaNO}_{2}$, and $\mathrm{NaF}$ ) metal ions were purchased from Sinopharm Chemical Reagent Co. Ltd. Deionized water was used throughout all experiments.

\section{Synthesis of probe APA}

The synthetic route to fluorescent probe $\mathbf{E}$ is depicted in Figure S1. First, compound $\mathbf{B}$ was obtained in one step by a Lewis acid-catalyzed condensation reaction of commercial starting material $\mathbf{A}$ and paraformaldehyde. Subsequently, deprotection of compound $\mathbf{B}$ with boron tribromide in chloroform produced compound $\mathbf{C}$, which was further applied in the substitution reaction with methyl chloroacetate to achieve compound D. Finally, the desired product $\mathbf{E}$ was obtained via amidation of compound $\mathbf{D}$ with ethylenediamine. 


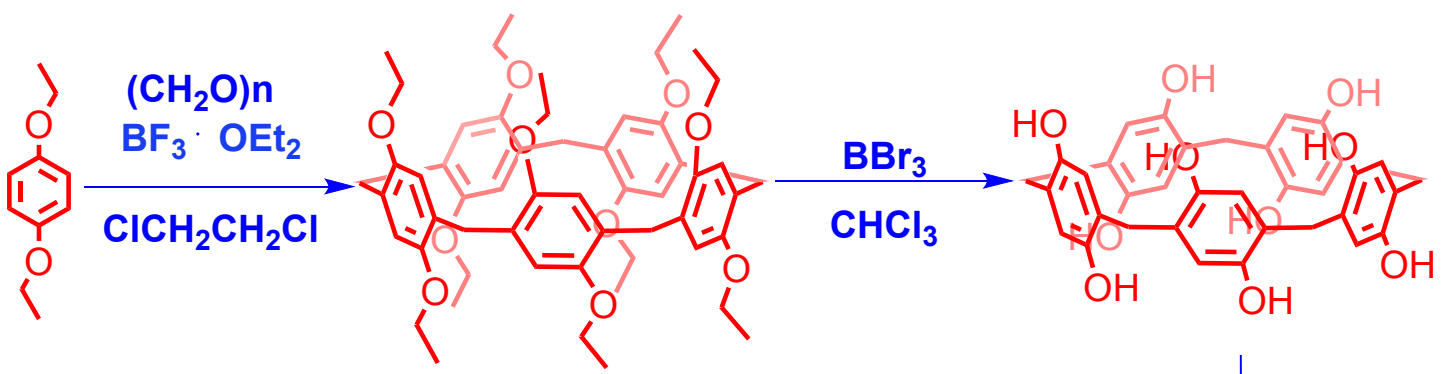

A

B $52 \%$
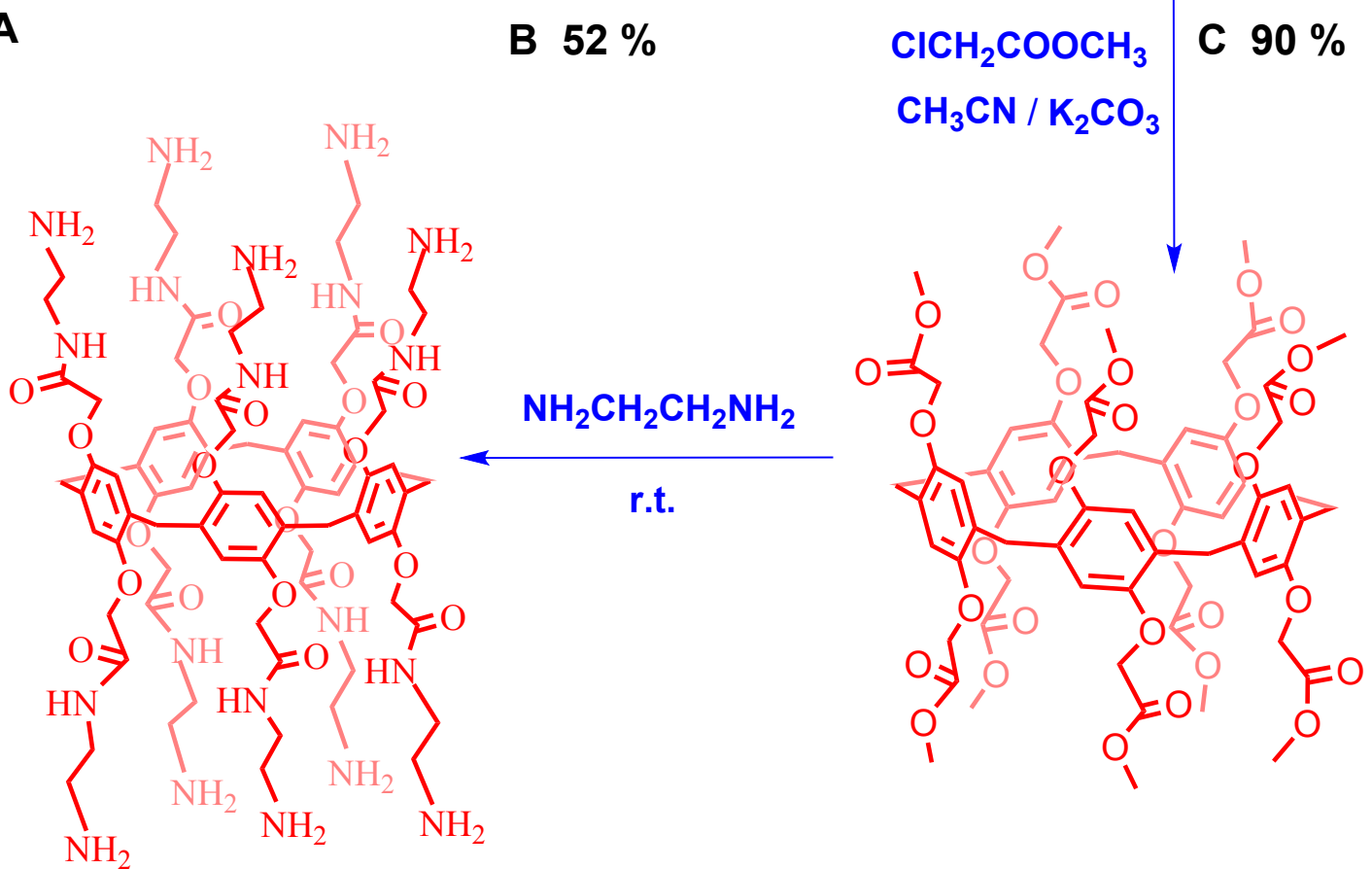

E $87 \%$

D $56 \%$

Figure S1 Synthetic route of fluorescent probe E from A-D.

\subsection{Synthesis of compound B}

Paraformaldehyde (2.8 g, $0.09 \mathrm{~mol})$ was added to a solution of 1,4-diethoxybenzene $(5.0 \mathrm{~g}, 0.03 \mathrm{~mol})$ in dry $\mathrm{ClCH}_{2} \mathrm{CH}_{2} \mathrm{Cl}(150 \mathrm{~mL})$ under a nitrogen atmosphere at $25^{\circ} \mathrm{C} . \mathrm{Next}, \mathrm{BF}_{3} \cdot \mathrm{OEt}_{2}(4.2 \mathrm{~mL})$ was added to the mixture, and the reaction was then stirred at $25^{\circ} \mathrm{C}$ for $90 \mathrm{~min}$. The mixture was then quenched with ethanol $(20 \mathrm{~mL})$. After stirring for $7 \mathrm{~min}$, the filtrate was collected. The filtrate was extracted 3 times with deionized water, and the organic phase was combined and dried by anhydrous sodium sulfate. After removal of the solvent, the obtained solid was dissolved in $\mathrm{CH}_{2} \mathrm{Cl}_{2}(30 \mathrm{~mL})$ and precipitated in EtOAc. The solid was recrystallized from $\mathrm{CH}_{2} \mathrm{Cl}_{2}$ and $n$-hexane to obtain a white solid B (2.8 g, Yield: 52\%). ${ }^{1} \mathrm{H}$ NMR (400 MHz, 
$\left.\mathrm{CDCl}_{3}\right) \delta(\mathrm{ppm}): 6.74(\mathrm{~s}, 10 \mathrm{H}), 3.86(\mathrm{q}, J=6.8 \mathrm{~Hz}, 20 \mathrm{H}), 3.77(\mathrm{~s}, 10 \mathrm{H}), 1.28(\mathrm{t}, J=6.8$ $\mathrm{Hz}, 30 \mathrm{H})$.

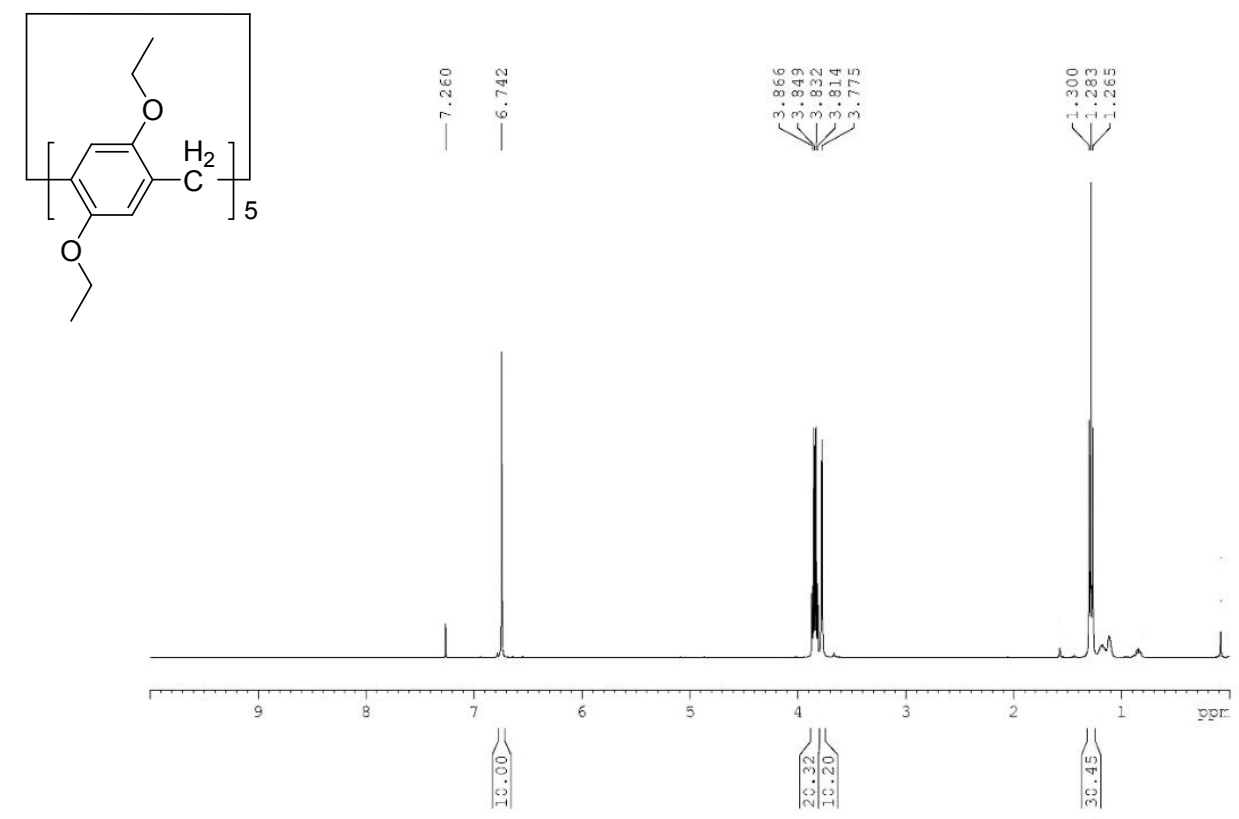

Figure S2 The ${ }^{1} \mathrm{H}$ NMR spectrum $\left(400 \mathrm{MHz}, \mathrm{CDCl}_{3}, 293 \mathrm{~K}\right)$ of $\mathbf{B}$.

\subsection{Synthesis of compound C}

Boron tribromide $(4.5 \mathrm{~mL}, 0.044 \mathrm{~mol})$ was slowly added to a solution of compound $\mathbf{B}(2.0 \mathrm{~g}, 0.022 \mathrm{~mol})$ in $\mathrm{CHCl}_{3}(100 \mathrm{~mL})$ under a nitrogen atmosphere at $-12{ }^{\circ} \mathrm{C}$. The reaction was then stirred at $25^{\circ} \mathrm{C}$ for $24 \mathrm{~h}$. The mixture was then quenched by ice water $(50 \mathrm{~mL})$ and stirred for $30 \mathrm{~min}$. Finally, the solid was collected by filtration and was washed by hydrochloric acid (36\%). Then, the samples were washed three times with $\mathrm{CHCl}_{3}$ and dried to get a white solid $\mathbf{C}(1.42 \mathrm{~g}$, Yield: $90 \%)$. ${ }^{1} \mathrm{H}$ NMR (400 MHz, DMSO) $\delta$ (ppm): 8.44 (s, 10H), 6.57 (s, 10H), $3.43(\mathrm{~s}, 10 \mathrm{H}) .{ }^{13} \mathrm{C}$ NMR (100 MHz, DMSO) $\delta$ (ppm): 146.5, 126.8, 117.7, 29.5. 


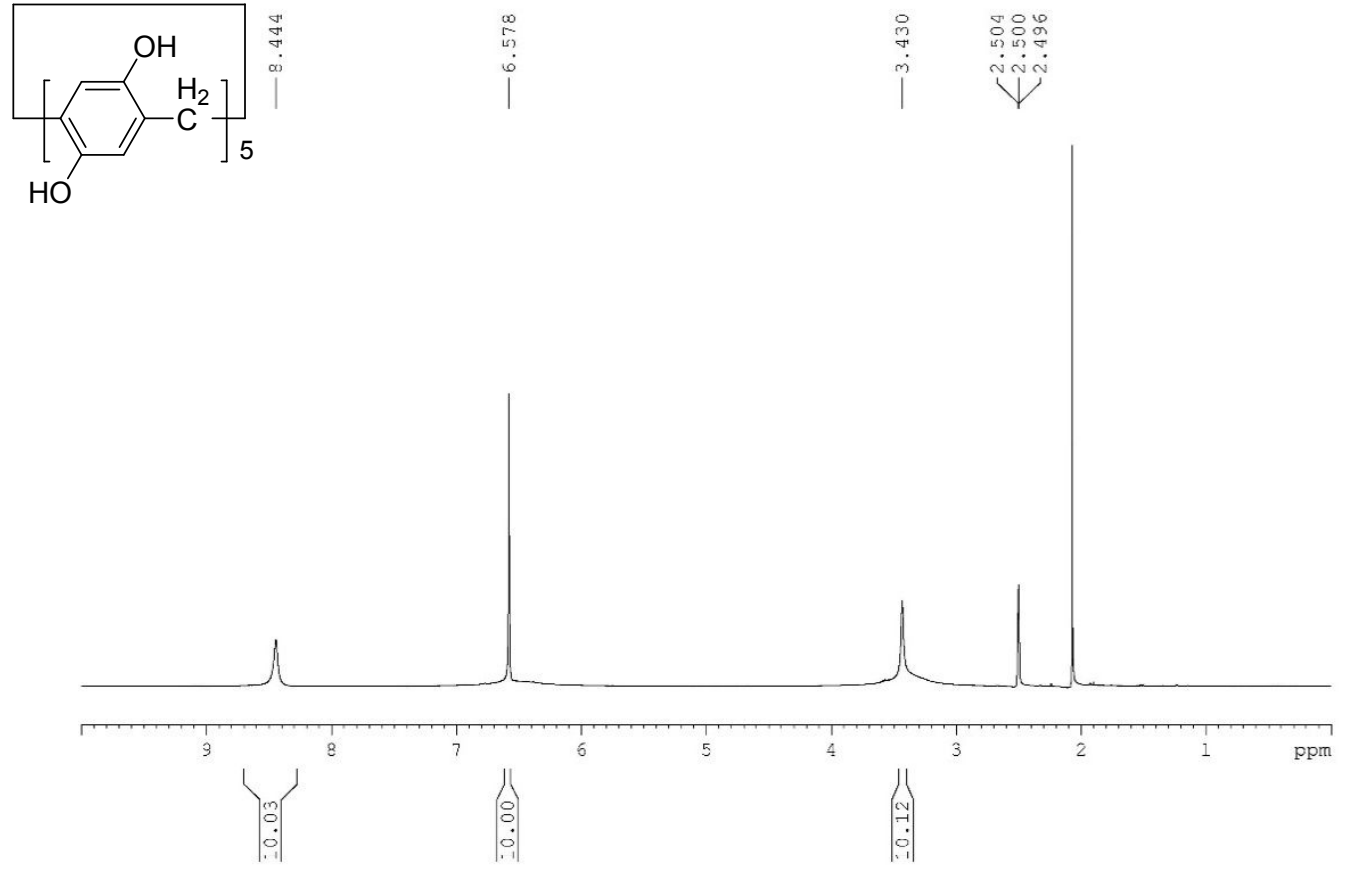

Figure S3 The ${ }^{1} \mathrm{H}$ NMR spectrum (400 MHz, DMSO, $293 \mathrm{~K}$ ) of $\mathbf{C}$.

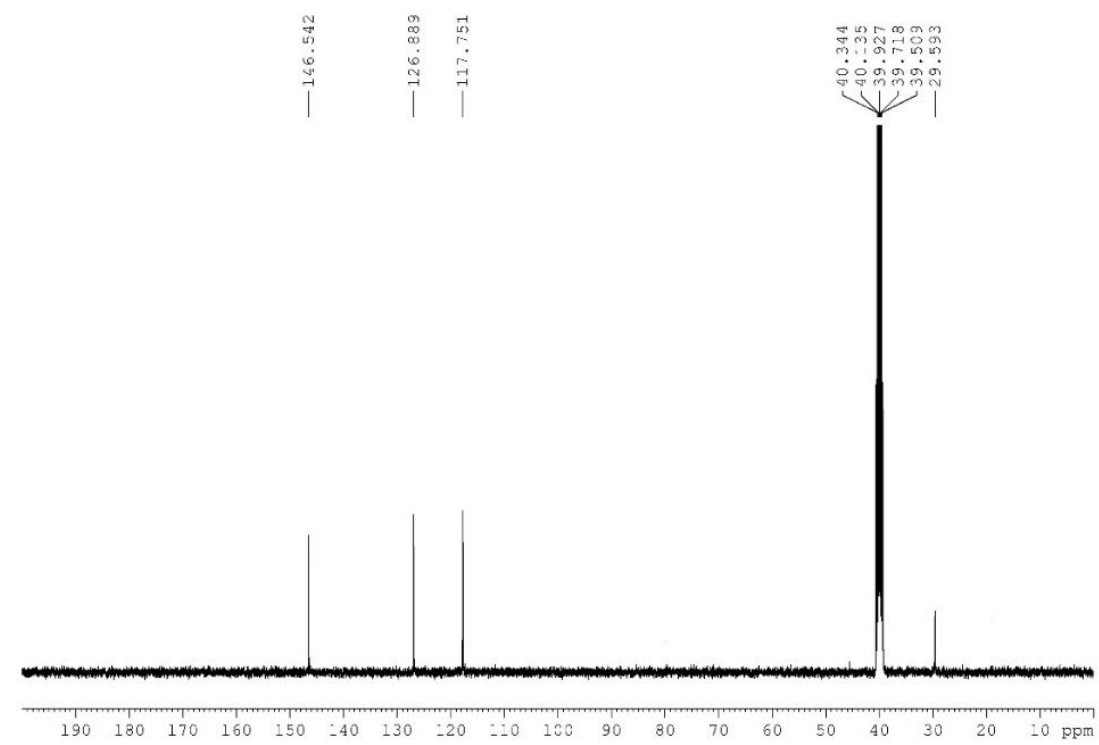

Figure S4 The ${ }^{13} \mathrm{C}$ NMR spectrum (400 MHz, DMSO, $293 \mathrm{~K}$ ) of C.

\subsection{Synthesis of compound D}

potassium carbonate $(10 \mathrm{~g}, 0.1 \mathrm{~mol})$ and methyl chloroacetate $(10 \mathrm{~mL}, 0.1 \mathrm{~mol})$ was sequentially added to a solution of compound $\mathbf{C}(1.5 \mathrm{~g}, 0.0025 \mathrm{~mol})$ in anhydrous 
$\mathrm{CH}_{3} \mathrm{CN}(60 \mathrm{~mL})$ under a nitrogen atmosphere. The reaction was stirred at $85{ }^{\circ} \mathrm{C}$ for 36 h. After washing with dichloromethane, the filtrate was collected. Then, the solvent was removed, and the solid was recrystallized from $\mathrm{CH}_{2} \mathrm{Cl}_{2}$ and $\mathrm{MeOH}$ to obtain a white solid D (1.87 g, Yield: $56 \%) .{ }^{1} \mathrm{H}$ NMR (400 MHz, $\left.\mathrm{CDCl}_{3}\right) \delta(\mathrm{ppm})$ : $6.98(\mathrm{~s}, 10 \mathrm{H}), 4.55(\mathrm{~s}, 20 \mathrm{H}), 3.85(\mathrm{~s}, 10 \mathrm{H}), 3.53(\mathrm{~s}, 30 \mathrm{H}) .{ }^{13} \mathrm{C} \mathrm{NMR}\left(100 \mathrm{MHz}, \mathrm{CDCl}_{3}\right)$ $\delta(\mathrm{ppm}): 169.7,148.8,128.4,114.4,65.4,51.9,29.2$.
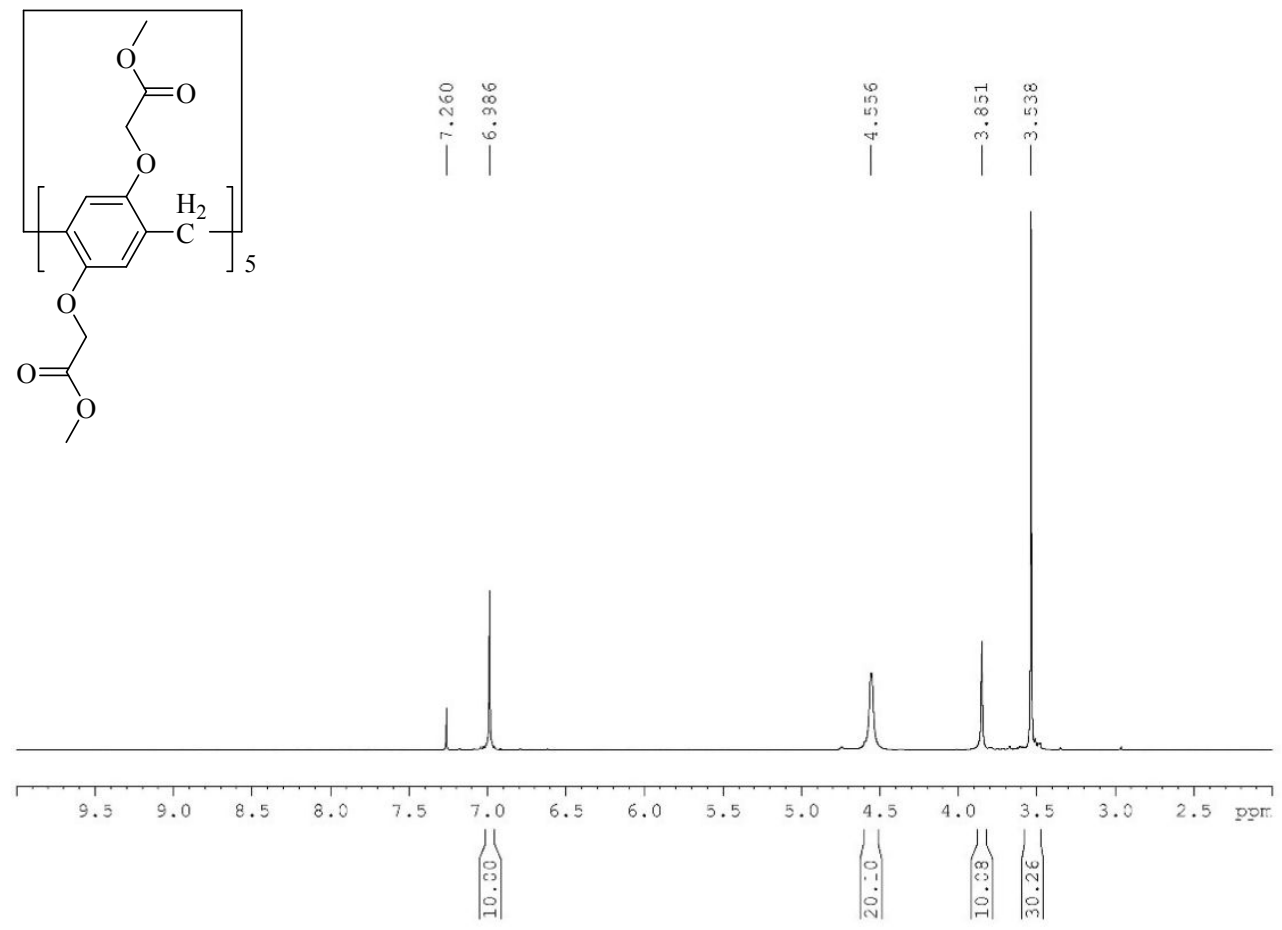

Figure S5 The ${ }^{1} \mathrm{H}$ NMR spectrum (400 MHz, $\left.\mathrm{CDCl}_{3}, 293 \mathrm{~K}\right)$ of D. 

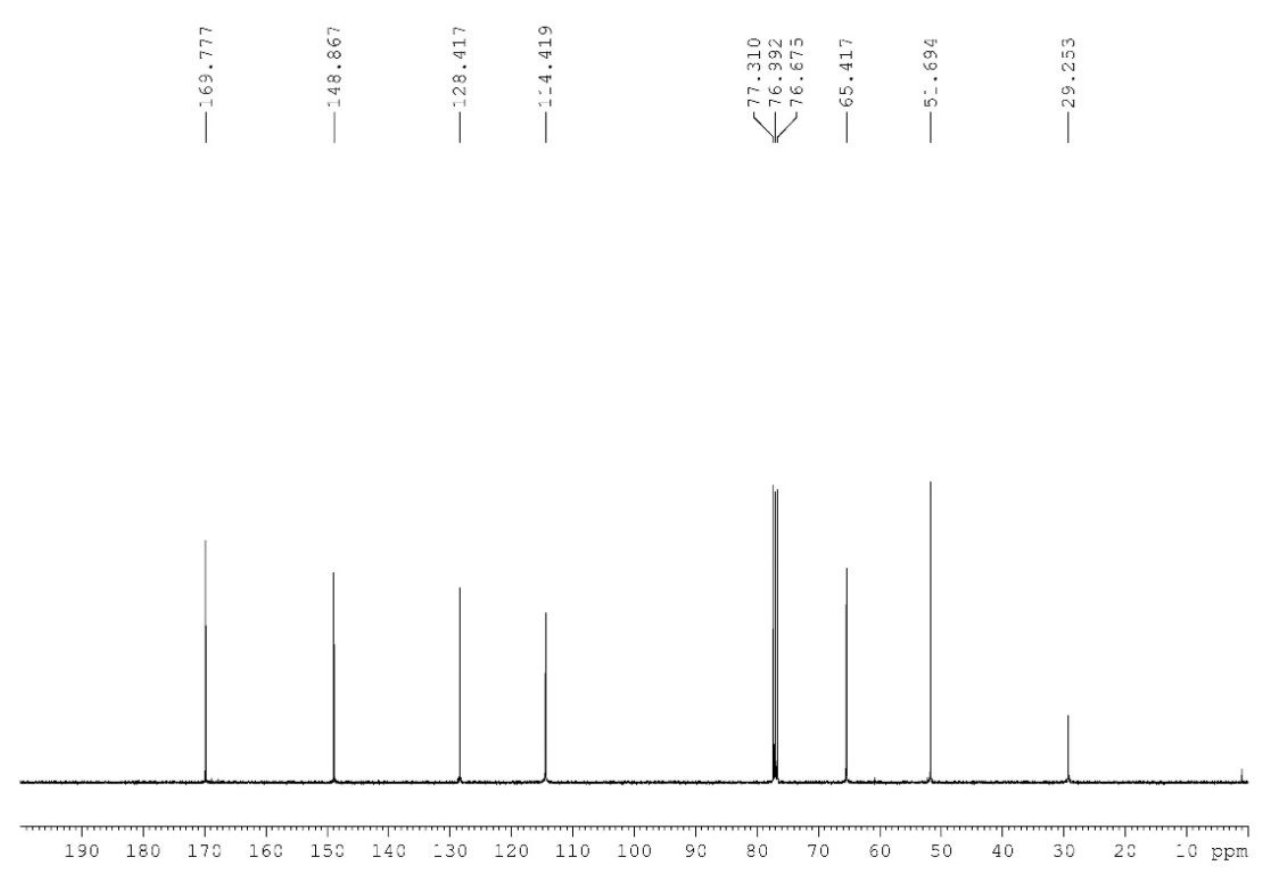

Figure S6 The ${ }^{13} \mathrm{C}$ NMR spectrum $\left(400 \mathrm{MHz}, \mathrm{CDCl}_{3}, 293 \mathrm{~K}\right)$ of D.

\subsection{Synthesis of compound $E$}

Compound D (1.33 g, $0.001 \mathrm{~mol}))$ was dissolved in ethylenediamine $(5 \mathrm{~mL})$ under a nitrogen atmosphere. The reaction was stirred at $110^{\circ} \mathrm{C}$ for $12 \mathrm{~h}$. Then, the solvent was removed, and the residue was dissolved in deionized water $(15 \mathrm{~mL})$ and finally extracted three times with $\mathrm{CHCl}_{3}$. The combined organic phase was washed with water, brined, dried by $\mathrm{Na}_{2} \mathrm{SO}_{4}$, filtered, and concentrated under reduced pressure to get a light-yellow solid E $(1.4 \mathrm{~g}$, Yield: $87 \%)$. Mp: $126-127^{\circ} \mathrm{C}$. IR $v_{\max }$ $\left(\mathrm{cm}^{-1}\right): 3,357,2,931,1,666,1,541,1,496,1,438,1,403,1,206,1,062,934,582 .{ }^{1} \mathrm{H}$ NMR (400 MHz, $\left.\mathrm{D}_{2} \mathrm{O}\right) \delta(\mathrm{ppm}): 6.88(\mathrm{~s}, 10 \mathrm{H}), 4.54$ (s, 20H), $3.88(\mathrm{~s}, 10 \mathrm{H}), 3.53-3.16$ (m, 20H), 2.97-2.40 (m, 20H). ${ }^{13} \mathrm{C}$ NMR (100 MHz, DMSO) $\delta$ (ppm): 168.3, 149.4, 128.4, 115.1, 68.2, 42.0, 41.2, 29.3. HRMS (ESI) $m / z$ calcd for $\mathrm{C}_{75} \mathrm{H}_{111} \mathrm{~N}_{20} \mathrm{O}_{20}$ $[\mathrm{M}+\mathrm{H}]^{+}$1611.8278; found 1611.8277. 


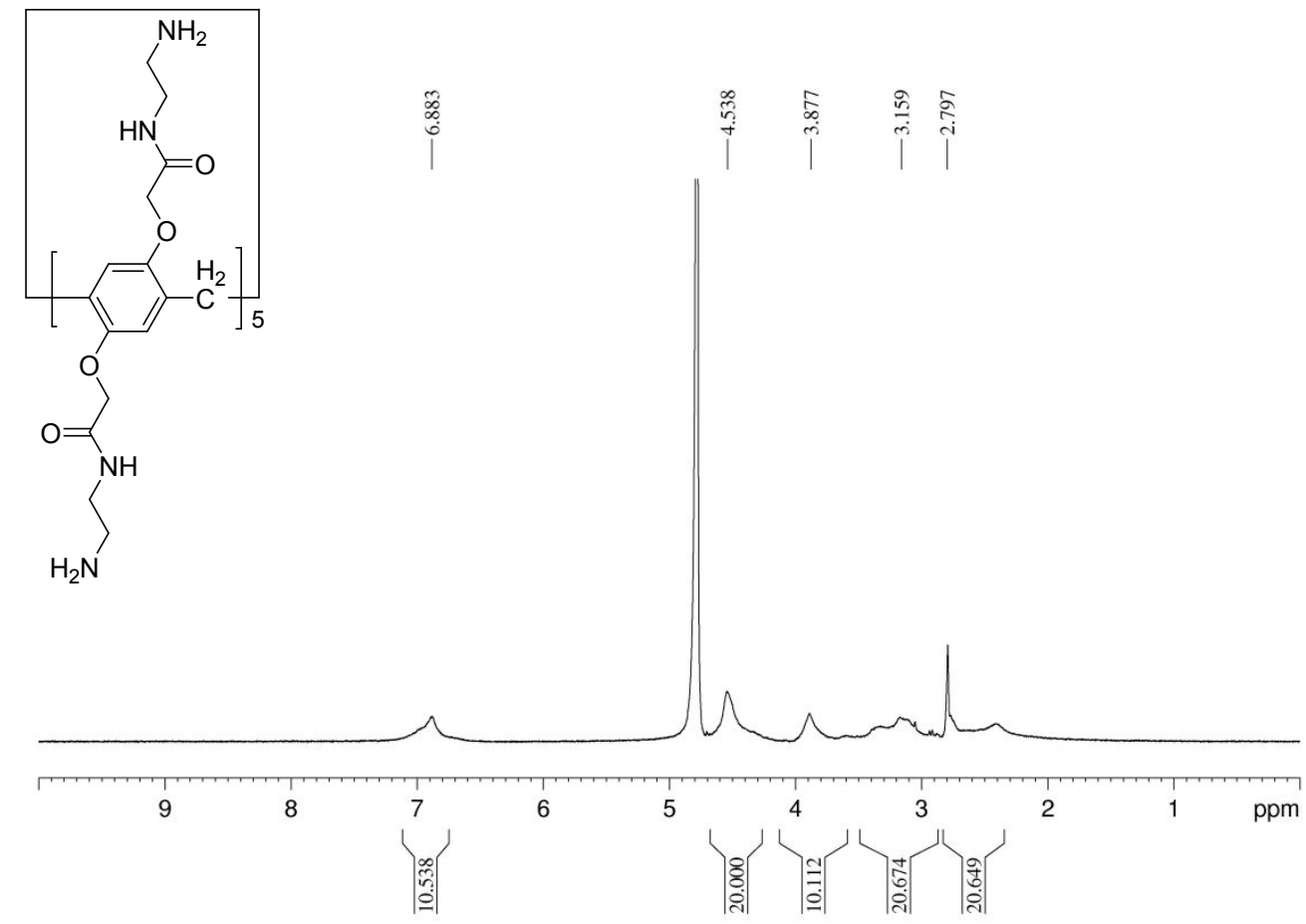

Figure S7 The ${ }^{1} \mathrm{H}$ NMR spectrum $\left(400 \mathrm{MHz}, \mathrm{D}_{2} \mathrm{O}, 293 \mathrm{~K}\right)$ of $\mathbf{E}$.

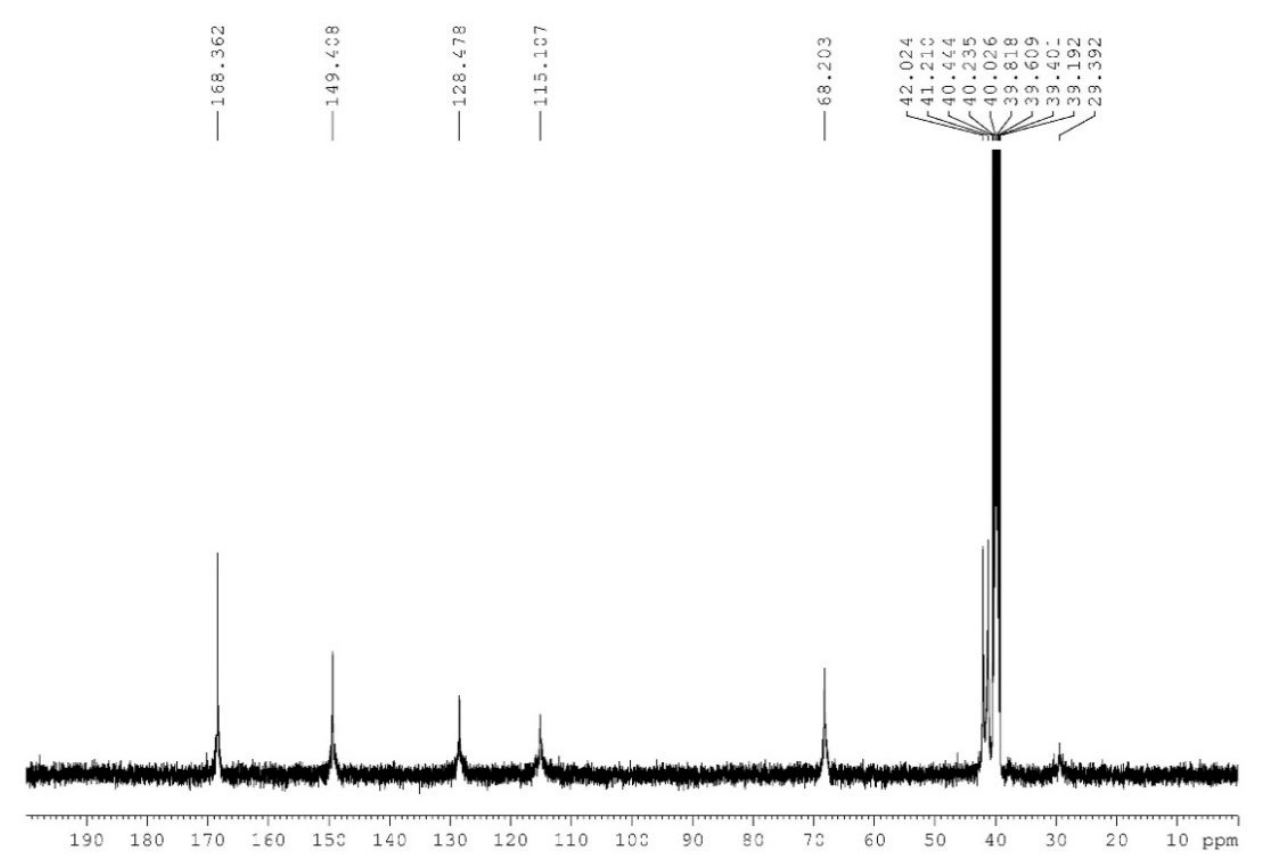

Figure S8 The ${ }^{13} \mathrm{C}$ NMR spectrum (400 MHz, DMSO, $293 \mathrm{~K}$ ) of E. 
MS Formula Results: + Scan (0.2130 min) Sub (xyp-3+++.d)

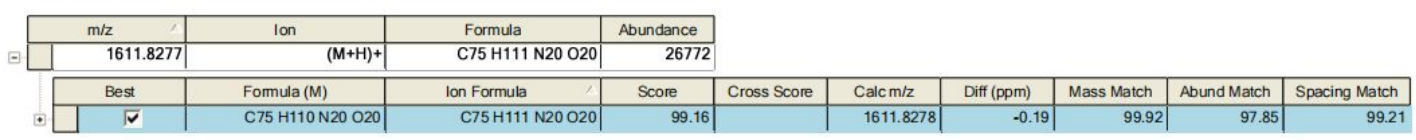

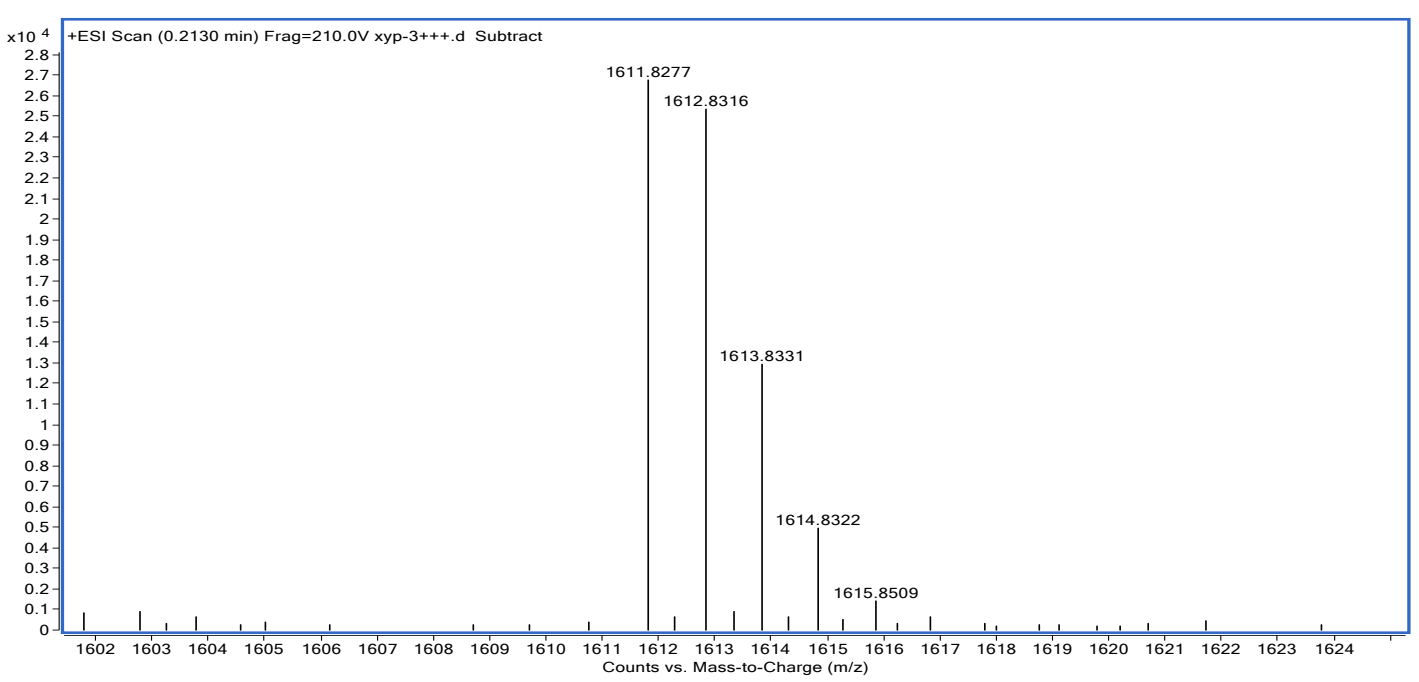

Figure S9 The mass spectrum of $\mathbf{E}$.

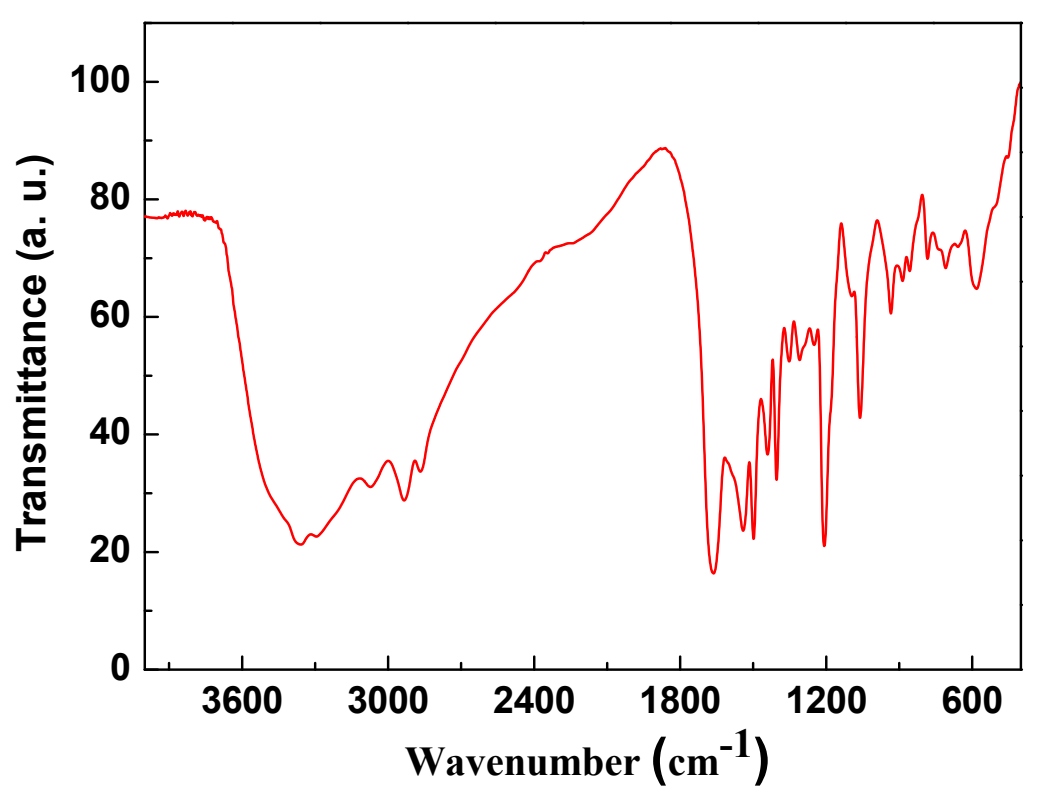

Figure S10 The infrared spectrum of $\mathbf{E}$. 